\title{
Welcome to Veterinary Medicine: Research and Reports
}

This article was published in the following Dove Press journal:

Veterinary Medicine: Research and Reports

9 September 201 I

Number of times this article has been viewed

\section{Jeffrey MB Musser}

Department of Veterinary Pathobiology, College of Veterinary Medicine, Texas A\&M University, TX, USA
Correspondence: Jeffery MB Musser Department of Veterinary Pathobiology, College of Veterinary Medicine, Texas A\&M University, TX, USA

Tel +l 9794580527

Email jmusser@cvm.tamu.edu
This year marks the 250th anniversary of the Royal Veterinary School in Lyon, France, the world's first veterinary college. Since its inception, many changes have occurred in veterinary medicine such as views on education and didactic learning, demographics of our profession, and standards of practice in animal husbandry, medicine, surgery, anesthesia, and vaccinology. In fact, the concept of infectious diseases has changed - remember the germ theory was proposed a mere 140 years ago. However, one constant tenet in our profession has been the need to disseminate progresses, innovations, advances, and developments in veterinary sciences. Published reports are the foundation for the growth of medicine and science. What would the state of medicine be if Pasteur, Koch, Bourgelat, or Theobald Smith had not published their works?

From the first volumes of the Veterinary Journal and Annals of Comparative Pathology and the American Veterinary Review, 1875 and 1877 respectively, which contained general veterinary news, editorials, scientific articles, and case reports, many other excellent journals have continued to circulate information to practitioners, scientists, and researchers. These journals were bound, hard copy periodicals sent to individuals and libraries that had purchased them. But, today's technology is transforming the process of information dissemination and publishing. Computers, iPads, notebooks, and smart phones are allowing us to go paperless with more timely and extensive access to publications and information.

A new model of publishing is setting the standard for periodicals - Open Access. Open Access does not charge readers or institutions for the use of the journal. The user is free to read, download, copy, share, or print articles of interest. Articles published in Open Access are available anywhere there is access to the World Wide Web, thus providing a venue for wider distribution and increased efficiency and use of the material. However, Open Access publication is only a model for distribution. Just as important, or perhaps even more important, is the quality of the information that is distributed. If a journal contains articles of low scientific merit, it is a poor quality journal and few care how easily it can be accessed or shared. So what characteristics make a "quality" journal? For simplicity's sake, and as a food animal veterinarian I like simplicity, the characteristics of a quality journal can be listed as 1) accessibility and dissemination, 2) timeliness, and 3) article worth. So what about Veterinary Medicine: Research and Reports; is it a quality journal?

On the issue of accessibility and dissemination, Open Access, as stated previously, provides a venue for wider distribution; there are no restrictions on accessing 
the journal. Additionally, Veterinary Medicine: Research and Reports is cited in the CAB Abstracts database and will shortly be included on the MEDLINE database, expanding the journal's prospective impact.

Unique to electronic publishing is the ability to provide "video abstracts". Video abstracts are an innovative addition to papers where authors can give a $1-4$ minutes presentation to provide an overview of their paper or demonstrate a surgical procedure or technique reported in the paper. The application is limited only by the author's imagination and editorial staff's discretion. (Please see more about video abstracts on our webpage [www.dovepress.com]). Thus, our journal meets the first criteria of a quality journal - that of adequate dissemination. Now, how about timeliness?

The aim of Veterinary Medicine: Research and Reports is to report on the rapidly advancing state of our profession in a timely manner. For authors, this translates to a quick turnaround time. The editorial staff has set a goal of 12-15 days from receiving a manuscript to the first editorial discussion and of 15-25 days from receipt of revision to publication. Generally, the peer review process is complete within 2-3 weeks and the editor's decision within 48 hours of this. As can be deduced, the author's promptness in addressing reviewers' comments and submitting a revision will determine the eventual interval to publication. Promptness in publication with quicker dissemination of the work is a great advantage to authors, who are more accustomed (or should I say frustrated) to months passing from submission to publication. But what about the benefit to readers? For readers, this promptness in publishing means access to the most current peer reviewed scientific information and discoveries, a definite advantage in this era of fast paced research. However, if the quality of the peer review process is subpar, resulting in mediocre articles and information, timeliness and availability of the journal is of no advantage to the authors or readers.
Every submission to Veterinary Medicine: Research and Reports goes through a rigorous peer review process comprised of initial manuscript scrutiny by the Dove Press' excellent editorial staff, then a minimum of two reviews by topic area experts, and finally evaluation of the manuscript and reviews by the editor-in-chief. New journals are gauged by the quality of the articles and we are dedicated to setting and obtaining high standards. Our editorial board is comprised of experts from around the world - Africa, Asia, Europe, the Middle East, and North America - and from disciplines encompassing the breadth of veterinary medicine. Their reviews are thorough and exacting; in fact, some authors find that our peer reviewers' comments substantially add to their final papers. Additionally, Dove Press has a proven track record for quality publication and journals. Presently, Dove Press has approximately 112 journals in an Open Access forum, and I invite you to check them out as well.

In summary, our journal seeks to provide a venue for wider distribution of original research, case reports, reviews (invited and unsolicited), and editorials and commentaries pertaining to all areas of veterinary medicine. Original studies in all disciplines of veterinary medicine that lead to the improvement of clinical practices and the advancement of knowledge are highly welcomed. Our goal is to become a quality journal respected by authors and readers alike. Some colleagues view the Open Access forum as somehow less prestigious. Electronic publishing is not a mechanism to destroy hard copy journals, but a mode to augment the timely dissemination of good science, which can only benefit science and enhance the reputation of any journal. Veterinary Medicine: Research and Reports will not compromise on our editorial standards and looks forward to providing you with a "quality" journal. You decide!
Veterinary Medicine: Research and Reports

\section{Publish your work in this journal}

Veterinary Medicine: Research and Reports is an international, peer-reviewed, open access journal publishing original research, case reports, editorials, reviews and commentaries on all areas of veterinary medicine. The manuscript management system is completely online and includes a very quick and fair peer-review system.

Submit your manuscript here: http://www.dovepress.com/veterinary-medicine-research-and-reports-journal

\section{Dovepress}

Visit http://www.dovepress.com/testimonials.php to read real quotes from published authors. 